Full Paper

\title{
Aluminum(III) Porphyrins as Ionophores for Fluoride Selective Polymeric Membrane Electrodes
}

\author{
Jeremy T. Mitchell-Koch, ${ }^{\mathrm{b}}$ Mariusz Pietrzak, ${ }^{\mathrm{c}}$ Elzbieta Malinowska, ${ }^{\mathrm{c}}$ Mark E. Meyerhoff*a \\ a Chemistry Department, University of Michigan, Ann Arbor, MI 48109, USA \\ *e-mail: mmeyerho@umich.edu \\ b Department of Chemistry, Emporia State University, Emporia, KS 66801, USA \\ c Department of Chemistry, Warsaw University of Technology, Warsaw, Poland
}

Received: December 22, 2005

Accepted: January 17, 2006

\begin{abstract}
Aluminum(III) porphyrins are examined as potential fluoride selective ionophores in polymeric membrane type ionselective electrodes. Membranes formulated with $\mathrm{Al}$ (III) tetraphenyl (TPP) or octaethyl (OEP) porphyrins are shown to exhibit enhanced potentiometric selectivity for fluoride over more lipophilic anions, including perchlorate and thiocyanate. However, such membrane electrodes display undesirable super-Nernstian behavior, with concomitant slow response and recovery times. By employing a sterically hindered $\mathrm{Al}(\mathrm{III})$ picket fence porphyrin (PFP) complex as the membrane active species, fully reversible and Nernstian response toward fluoride is achieved. This finding suggests that the super-Nernstian behavior observed with the nonpicket fence metalloporphyrins is due to the formation of aggregate porphyrin species (likely dimers) within the membrane phase. The steric hindrance of the PFP ligand structure eliminates such chemistry, thus leading to theoretical response slopes toward fluoride. Addition of lipophilic anionic sites into the organic membranes enhances response and selectivity, indicating that the $\mathrm{Al}$ (III) porphyrin ionophores function as charged carrier type ionophores. Optimized membranes formulated with $\mathrm{Al}$ (III)PFP in an $o$-nitrophenyloctyl ether plasticized PVC film exhibit fast response to fluoride down to $40 \mu \mathrm{M}$, with very high selectivity over $\mathrm{SCN}^{-}, \mathrm{ClO}_{4}^{-}, \mathrm{Cl}^{-}, \mathrm{Br}^{-}$and $\mathrm{NO}_{3}^{-}\left(k^{\text {pot }}<10^{-3}\right.$ for all anions tested). With further refinements in the membrane chemistry, it is anticipated that $\mathrm{Al}$ (III) porphyrin-based membrane electrodes can exhibit potentiometric fluoride response and selectivity that approaches that of the classical solid-state $\mathrm{LaF}_{3}$ crystal-based fluoride sensor.
\end{abstract}

Keywords: Porphyrins, Ionophores, Fluoride selective electrodes, Potentiometry

DOI: 10.1002/elan.200503450

\section{Introduction}

The development of ion-selective polymeric membrane electrodes has provided simple and inexpensive analytical tools for the determination of a large number of ionic species in complex sample matrixes [1,2]. Such devices have had an immense real-world impact, especially in the area of clinical chemistry for the determination of electrolytes in undiluted blood samples. While ion-selective membranes for cations are now well established, devising analogous devices with highly selective response to given anions has been far more challenging. This is due to the inherent differences between anions and cations, such as size and shape [3]. Under simple ion-exchange conditions, anion selectivity is governed by the partitioning of each anion from the aqueous sample phase into the organic membrane phase of the electrode; more lipophilic ions are exchanged more readily and thus display greater EMF response. The Hofmeister series is based on the anions' free energy of hydration $\left(\Delta G_{\text {hyd }}\right)$ and accurately predicts the selectivity pattern that occurs when membranes are doped with lipophilic anion exchangers such

Electroanalysis 18, 2006, No. 6, 551-557 as quaternary ammonium salts (i.e., $\mathrm{ClO}_{4}^{-}>\mathrm{SCN}^{-}>\mathrm{I}^{-}$, $>\mathrm{NO}_{3}{ }^{-}>\mathrm{Br}^{-}>\mathrm{Cl}^{-}>\mathrm{HCO}_{3}^{-}>\mathrm{F}^{-}$) [4].

The challenge in developing new anion polymeric selective membrane electrodes is to formulate films that exhibit responses that deviate from the Hofmeister series. This can be achieved by adding lipophilic agents to the membrane that selectively form complexes with one anion over others. Several reports from our laboratories [5-12], and elsewhere [13-15], have shown that metalloporphyrins can serve as useful ionophores for preparing membrane electrodes with selectivity toward a variety of different anions. When using metalloporphyrins as ionophores, selectivity for a particular ion arises from its preferred axial ligation to the central metal ion of the porphyrin complex. Examples of this ligation phenomenon include indium(III)'s preference for chloride [12], cobalt(III) for nitrite [10], and gallium(III) and zirconium(IV) for fluoride $[6,7,9,12]$.

Constructing polymer membrane-based anion ISEs for fluoride presents an especially formidable challenge due to fluoride's extremely negative $\Delta G_{\text {hyd }}(-436 \mathrm{~kJ} / \mathrm{mol})$ [16]. In addition to representing a fundamental advance in ISE 
technology, the development of a fluoride-selective polymeric membrane electrode could also have great impact for several real-world applications. Fluoride is present in a number of oral hygiene products and is also added to many municipal water supplies to help prevent dental carries [17]. When employing fluoride in this manner, there is a relatively small therapeutic window: too low $\left[\mathrm{F}^{-}\right]$will be ineffective and too much can cause damage (dental fluorosis). Therefore, accurate determination is critical. Further, several pesticides and chemical warfare agents contain organophosphate groups with $\mathrm{C}-\mathrm{F}$ bonds that may hydrolyzed, producing $\mathrm{F}^{-}$, when exposed to the environment. Detection of this fluoride can be employed as a marker to assist in determining the presence of such compounds. It may also be possible to use a fluoride sensor in combination with an enzyme to quantify specific compounds [18]. Additionally, antidepressant pharmaceuticals such as (R)-fluoxetine (prozac) contain $\mathrm{C}-\mathrm{F}$ bonds [19], and sensitive fluoride detection could assist in more fully elucidating the metabolic pathway of these compounds.

Due to these important applications, fluoride-selective sensor development has been an area of great interest. The widely used lanthanide fluoride $\left(\mathrm{LaF}_{3}\right)$ crystal based electrode [20] is accurate and sensitive, but also suffers from certain drawbacks including high cost and difficulty to miniaturize, especially for incorporation into planar sensor arrays. The ability to utilize polymer membrane-based sensors to accurately detect fluoride would solve many of the limitations encountered with the $\mathrm{LaF}_{3}$ electrode. Previously, both $\mathrm{Ga}(\mathrm{III})$ and $\mathrm{Zr}(\mathrm{IV})$ porphyrins have been added to polymer membranes and electrodes fabricated with such membranes were shown to exhibit enhanced potentiometric response toward fluoride [6, 7, 9, 12]. In addition to these porphyrin-based systems, uranyl salophens [21], bis(halodiphenylstannyl)alkanes [22], and gallium salophens [23] have been previously reported to enhance fluoride response when employed as ionophores in potentiometric ISE membranes.

Very recently, we have reported that aluminum(III) octaethylporphyrin ( $\mathrm{Al}(\mathrm{III})-\mathrm{OEP})$ in thin polymer films can be used to devise a highly selective optical sensor for fluoride $[24,25]$. In these studies, the change in optical absorbance of a $\mathrm{pH}$ sensitive chromoionophore is utilized as transduction of the fluoride binding to the $\mathrm{Al}(\mathrm{III})$ porphyrin within the polymeric film. When a fluoride ion is extracted into the membrane phase, a proton is co-extracted to maintain electroneutrality within the film. The porphyrin complex binds the fluoride while the proton is bound by the chromoionophore, whose optical absorbance is highly dependent on its degree of protonation. Herein we report initial results when employing aluminum(III) porphyrins (TPP, OEP, and PFP (picket-fence porphyrin)) as fluoride selective ionophores in potentiometric polymer membrane ISEs. The data suggest that both $\mathrm{Al}(\mathrm{III})$-TPP and OEP complexes undergo dimer-monomer equilibria within the polymer membranes of the electrode, but that the sterically hindered PFP does not participate in such reactions. It will be shown that eliminating the dimer-monomer chemistry provides a fluoride sensor that exhibits improved analytical performance and response characteristics, along with exceptional selectivity for fluoride ion.

\section{Experimental}

\subsection{Reagents and Chemicals}

The ionophore, aluminum(III) octaethylporphyrin chloride (Al(III)-OEP) was purchased from Frontier Scientific. Aluminum(III) 5,10,15,20-tetraphenylporphyrin chloride (Al(III)-TPP) was synthesized using previously published procedures.[26, 27] The picket fence porphyrin $(5,10,15,20-$ tetrakis(o-pivalamidophenyl)porphyrin), obtained from Frontier Scientific, Logan, UT, was metallated with diethylaluminum chloride as described previously (only for nonsterically hindered species in these previous reports) to provide $\mathrm{Al}(\mathrm{III})$-PFP $[28,29]$. Unless otherwise noted, solvents and reagents were used as received from Aldrich (Milwaukee, WI), Fisher (Pittsburgh, PA), Strem Chemicals (Newburyport, MA), or Fluka (Milwaukee, WI). Solvents used for synthesis under an inert atmosphere were further purified using standard procedures [30].

\subsection{ISE Membrane Formulation and EMF Measurements}

The ISE membranes consisted of $1 \mathrm{wt} \%$ ionophore and various quantities of anionic additive salt, potassium tetrakis[3,5-bis(trifluoromethyl)phenyl]borate (KTFPB), in ca. $66 \mathrm{wt} \%$ plasticizer (o-nitrophenyloctyl ether (oNPOE) or dioctylsebacate (DOS)) and ca. $33 \mathrm{wt} \%$ polymer (poly(vinyl chloride) (PVC)). For detailed compositions of the different membrane formulations tested, see Table 1. All components (total mass $=200 \mathrm{mg}$ ) were dissolved in 3 $4 \mathrm{~mL}$ of freshly distilled THF and the mixture was cast in a $25 \mathrm{~mm}$-id glass ring affixed to a glass slide. After allowing the solvent to evaporate overnight, disks $8 \mathrm{~mm}$ in diameter were cut from the parent membrane and mounted in appropriate electrode bodies (Oesch Sensor Technology, Sargans, Switzerland). Electrochemical potentials were measured with the following galvanic cell: $\mathrm{Ag} / \mathrm{AgCl}(\mathrm{s})$, $\mathrm{KCl}$ (4 M)/bridge electrolyte/sample solution/ion-selective membrane/inner filling solution $/ \mathrm{AgCl}(\mathrm{s}) / \mathrm{Ag}$. The bridge electrolyte of the double junction reference electrode was $1 \mathrm{M}$ lithium acetate. Buffered solutions of either $0.01 \mathrm{M}$ $\mathrm{NaCl}$ or $0.01 \mathrm{M} \mathrm{NaCl}$ with $0.01 \mathrm{M} \mathrm{NaF}$ served as the inner filling and conditioning solution for the ISE measurements. Buffers employed in this study included $0.05 \mathrm{M} \mathrm{2-[N-}$ morpholino]ethanesulfonic acid (MES) at $\mathrm{pH} 5.5$ and $0.05 \mathrm{M}$ glycine adjusted to $\mathrm{pH} 3.0$ with phosphoric acid (gly/phos). All analyte solutions were prepared from sodium salts of the various anions dissolved in the appropriate buffer.

EMF values for the ISEs vs. reference electrode were measured at ambient temperature (ca. $23^{\circ} \mathrm{C}$ ) via a $\mathrm{PC}$ coupled to a high $\mathrm{Z}$ interface (VF-4, World Precision 
Instruments) and controlled by Labview software (version 7.0, National Instruments). Data presented in the figures were normalized in order to make the starting EMF values of all electrodes equal to zero.

\subsection{Preparation of Films for Optical Studies}

A $100 \mathrm{mg}$ portion of the parent film cast for potentiometric measurements was dissolved in $3.3 \mathrm{~mL}$ of freshly distilled THF. A $400 \mu \mathrm{L}$ aliquot of this solution was then spread onto a glass slide $(55 \mathrm{~mm} \times 25 \mathrm{~mm} \times 1 \mathrm{~mm})$ and the slide was spun at $600 \mathrm{rpm}$ for $15 \mathrm{~s}$ with a Cookson Electronics G3 -8 spin coating device yielding a uniform polymer film for optical measurements. The slide was then cut to fit into a standard $1 \mathrm{~cm}$ quartz cell (ca. $50 \mathrm{~mm} \times 8 \mathrm{~mm} \times 1 \mathrm{~mm})$.

\subsection{Physical Methods}

For characterization of all synthesized species, all proton nuclear magnetic resonance $\left({ }^{1} \mathrm{H}\right.$ NMR) spectra were collected on a $400 \mathrm{MHz}$ Varian Inova spectrometer. Infrared spectra were collected on a Perkin Elmer Spectrum BX spectrometer. Mass spectra were recorded with a Micromass LCT-TOF mass spectrometer with positive ion electrospray ionozation. All electronic absorption spectra were collected using a Perkin Elmer Lamda 35, UV/Vis spectrophotometer. The glass slides containing polymer membranes were equilibrated in a large volume (ca. $100 \mathrm{~mL}$ ) of the appropriate analyte solution prior to collection of each optical spectrum.

\section{Results and Discussion}

\subsection{Potentiometric Response Characteristics of Membrane Electrodes Formulated with AI(III)-OEP and AI(III)-TPP}

The recent discovery that $\mathrm{Al}(\mathrm{III})-\mathrm{OEP}$ can be used as a highly selective fluoride ionophore in an optical sensing format $[24,25]$ led to the present study to examine various aluminum(III) porphyrins in polymer membranes for potentiometric sensing of fluoride. A variety of PVC membrane electrodes were prepared with various $\mathrm{Al}(\mathrm{III})$ porphyrins along with different amounts of anionic sites in the polymeric membranes, as well as different internal solution compositions (with and without fluoride added to internal) for the fabricated electrodes (see Table 1). Initial testing was performed with electrodes containing $\mathrm{Al}$ (III)TPP. As shown in Figure 1, devices prepared with PVCDOS membranes containing Al(III)-TPP (e.g., electrode III) exhibit enhanced potentiometric response to fluoride compared to all other anions tested. These results were obtained using $10 \mathrm{mM} \mathrm{NaCl}$ as the internal solution of the electrode and anionic additives (KTFPB; $50 \mathrm{~mol} \%$ relative to porphyrin) in the membrane. The addition of cationic sites in the form of tridodecylmethylammonium chloride (TDMAC) to the membrane phase yielded a classical Hofmeister selectivity pattern (data not shown), indicating that $\mathrm{Al}(\mathrm{III})$-TPP likely functions as a charged carrier type ionophore [31].

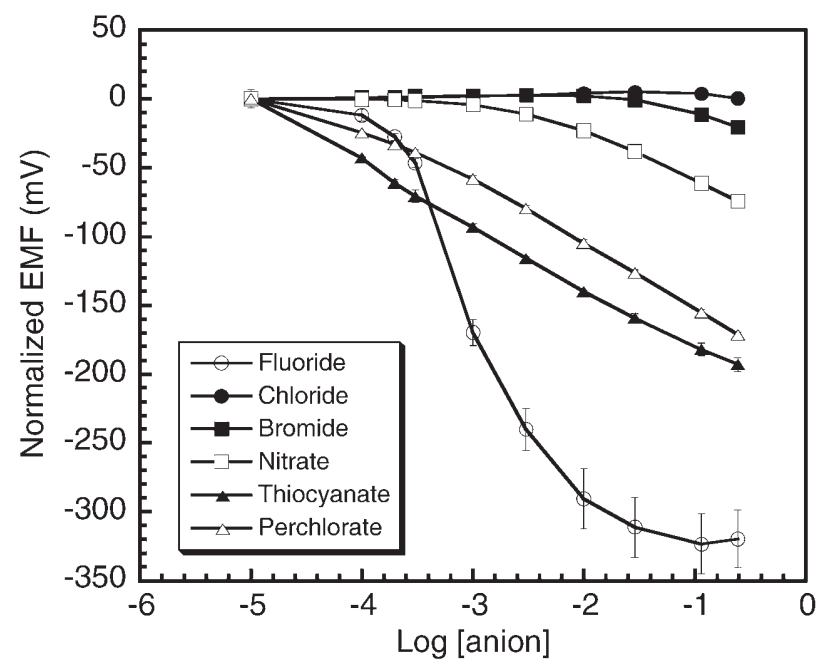

Fig. 1. Potentiometric anion responses of PVC/DOS electrode containing $\mathrm{Al}(\mathrm{III})-\mathrm{TPP}$ and $50 \mathrm{~mol} \%$ borate (relative to $\mathrm{Al}(\mathrm{III})$ ) (Electrode III). Internal solution: $0.01 \mathrm{M} \mathrm{NaCl}$. Sample buffer= $0.05 \mathrm{M}$ gly/phos, $\mathrm{pH} 3.0$.

In these preliminary experiments, the response to fluoride was assessed using a pH 3.0 glycine/phosphate buffer as the sample solution owing to the significant interference of hydroxide ions with the $\mathrm{Al}(\mathrm{III})$-porphyrin based membranes. Under such acidic conditions, ca. $60 \%$ of all fluoride present in solution is protonated (HF) and is not detected by the electrode. Hence, all potentiometric responses are plotted versus the logarithm of the anion's total concentration (i.e., $\left[\mathrm{F}^{-}\right]+[\mathrm{HF}]$ ). Activity of fluoride is not used due to the difficulty in determining accurate activity coefficients in zwitterionic buffer solutions.

Several levels of KTFPB were tested (see Table 1 for all membrane compositions) and the best selectivity for fluoride was obtained with $50 \mathrm{~mol} \%$ (relative to $\mathrm{Al}(\mathrm{III})$ TPP, membrane III). However, regardless of the borate concentration, the response to fluoride was slow and quite super-Nernstian with slopes greater than $-100 \mathrm{mV} /$ decade (see Table 1). Similar behavior was observed for membrane electrodes formulated with $\mathrm{Al}(\mathrm{III})$-OEP (data not shown).

The high slopes for the electrodes prepared with the Al(III)-TTP-doped membranes can likely be attributed to chemical changes in the organic membrane as fluoride ion levels are increased within the sample phase. It has been reported that other group 13 metalloporphyrins (Ga(III) and In(III)) form hydroxy-bridged dimer species [32], and that selective cleavage of these dimers by analyte ions $\left(\mathrm{F}^{-}\right.$ for $\mathrm{Ga}(\mathrm{III})$ and $\mathrm{Cl}^{-}$for $\mathrm{In}(\mathrm{III})$ ) is responsible for the observed non-Nernstian behavior.[33] Indeed, such dimer- 
Table 1. Summary of potentiometric slopes and detection limits to fluoride for film compositions of polymer membrane electrodes containing various aluminum(III) porphyrin ionophores.

\begin{tabular}{lllclrr}
\hline $\begin{array}{l}\text { Electrode } \\
\text { identity }\end{array}$ & Ionophore & Plasticizer & mol\% Borate & $\begin{array}{l}\text { Internal } \\
\text { solution }\end{array}$ & $\begin{array}{c}\mathrm{F}^{-} \text {Slope } \\
(\mathrm{mV} / \mathrm{dec})\end{array}$ & $\begin{array}{c}\text { Detection } \\
\text { limit }(\mathrm{M})\end{array}$ \\
\hline I & AlTPP & DOS & 0 & $\mathrm{Cl}$ & -123.9 & $1.1 \times 10^{-4}$ \\
II & AlTPP & DOS & 25 & $\mathrm{Cl}$ & -164.5 & $1.6 \times 10^{-4}$ \\
III & AlTPP & DOS & 50 & $\mathrm{Cl}$ & -162.9 & $1.4 \times 10^{-4}$ \\
IV & AlTPP & DOS & 75 & $\mathrm{Cl}$ & -169.8 & $1.3 \times 10^{-4}$ \\
V & AlTPP & DOS & 100 & $\mathrm{Cl}$ & -35.1 & $3.5 \times 10^{-5}$ \\
VI & AlTPP & DOS & 0 & $\mathrm{Cl} / \mathrm{F}$ & -67.3 & $3.0 \times 10^{-5}$ \\
VII & AlTPP & DOS & 25 & $\mathrm{Cl} / \mathrm{F}$ & -56.1 & $2.0 \times 10^{-5}$ \\
VIII & AlTPP & DOS & 50 & $\mathrm{Cl} / \mathrm{F}$ & -55.0 & $2.1 \times 10^{-5}$ \\
IX & AlTPP & DOS & 75 & $\mathrm{Cl} / \mathrm{F}$ & -46.6 & $3.4 \times 10^{-5}$ \\
X & AlOEP & DOS & 0 & $\mathrm{Cl} / \mathrm{F}$ & -64.6 & $1.2 \times 10^{-5}$ \\
XI & AlOEP & DOS & 25 & $\mathrm{Cl} / \mathrm{F}$ & -54.5 & $5.2 \times 10^{-5}$ \\
XII & AlOEP & DOS & 50 & $\mathrm{Cl} / \mathrm{F}$ & -15.1 & $1.4 \times 10^{-4}$ \\
XIII & AlOEP & DOS & 75 & $\mathrm{Cl}$ & -55.3 & $1.5 \times 10^{-4}$ \\
XIV & AlPFP & NPOE & 0 & $\mathrm{Cl}$ & -59.4 & $2.0 \times 10^{-4}$ \\
XV & AlPFP & NPOE & 25 & $\mathrm{Cl}$ & -57.6 & $4.1 \times 10^{-5}$ \\
XVI & AlPFP & NPOE & 50 & $\mathrm{Cl}$ & -54.2 & $3.5 \times 10^{-4}$ \\
XVII & AlPFP & DOS & 0 & $\mathrm{Cl}$ & -55.0 & $1.2 \times 10^{-4}$ \\
XVIII & AlPFP & DOS & 25 & $\mathrm{Cl}$ & -50.2 & $1.9 \times 10^{-4}$ \\
XIX & AlPFP & DOS & 50 & & & \\
\hline
\end{tabular}

monomer chemistry has already been employed to construct optical sensors for chloride [34] and gaseous amines [35] since the dimeric and monomeric forms of the porphyrins exhibit significant differences in their $\lambda_{\max }$ for UV-Vis absorption. For the aluminum(III) porphyrin systems reported here, membrane electrodes equilibrated and conditioned with $10 \mathrm{mM}$ fluoride (added to the internal solution, electrodes VIII and XII) display near-Nernstian fluoride response (see Fig. 2) with $\mathrm{Al}$ (III)-TPP or $\mathrm{Al}$ (III)-OEP as the ionophore, and maintain a high degree of potentiometric fluoride selectivity (see Fig. 2). It is believed that the addition of fluoride to the internal solution helps eliminate any $\mu-\mathrm{OH}$ bridged dimer formation and further helps to force the $\mathrm{Al}(\mathrm{III})$ porphyrins to their preferred ligation state with fluoride, to yield near theoretical slopes. Unfortunately, the response times and reversibility of electrodes prepared with membranes VIII and XII are still relatively slow compared to typical polymer membrane ISEs. This may be due to a second dimer-monomer equilibrium involving the formation of dimeric species induced by increasing fluoride levels, in which two fluoride ions bridge two $\mathrm{Al}(\mathrm{III})$ porphyrins in the membrane phase [25, 36]. When comparing the OEP with TPP systems, it is clear that $\mathrm{Al}(\mathrm{III})-\mathrm{TPP}$ displays greater reversibility in EMF response than $\mathrm{Al}$ (III)-OEP as illustrated in Figure 3. The slow response and recovery times of both sensors, however, suggests that multiple equilibria are still occurring in the membrane phase beyond the desired single axial ligation of the fluoride ion to a monomeric $\mathrm{Al}$ (III) species.

Interestingly, optical studies of thin polymeric films containing the $\mathrm{Al}$ (III)-OEP and TPP species suggest the possible formation of a $\mu-\mathrm{F}^{-}$dimeric species [25]. Figure 4 shows optical absorbance spectra of films containing Al(III)-TPP. The film (membrane used for electrodes III/ VIII in Table 1) was initially equilibrated in gly/phos buffer
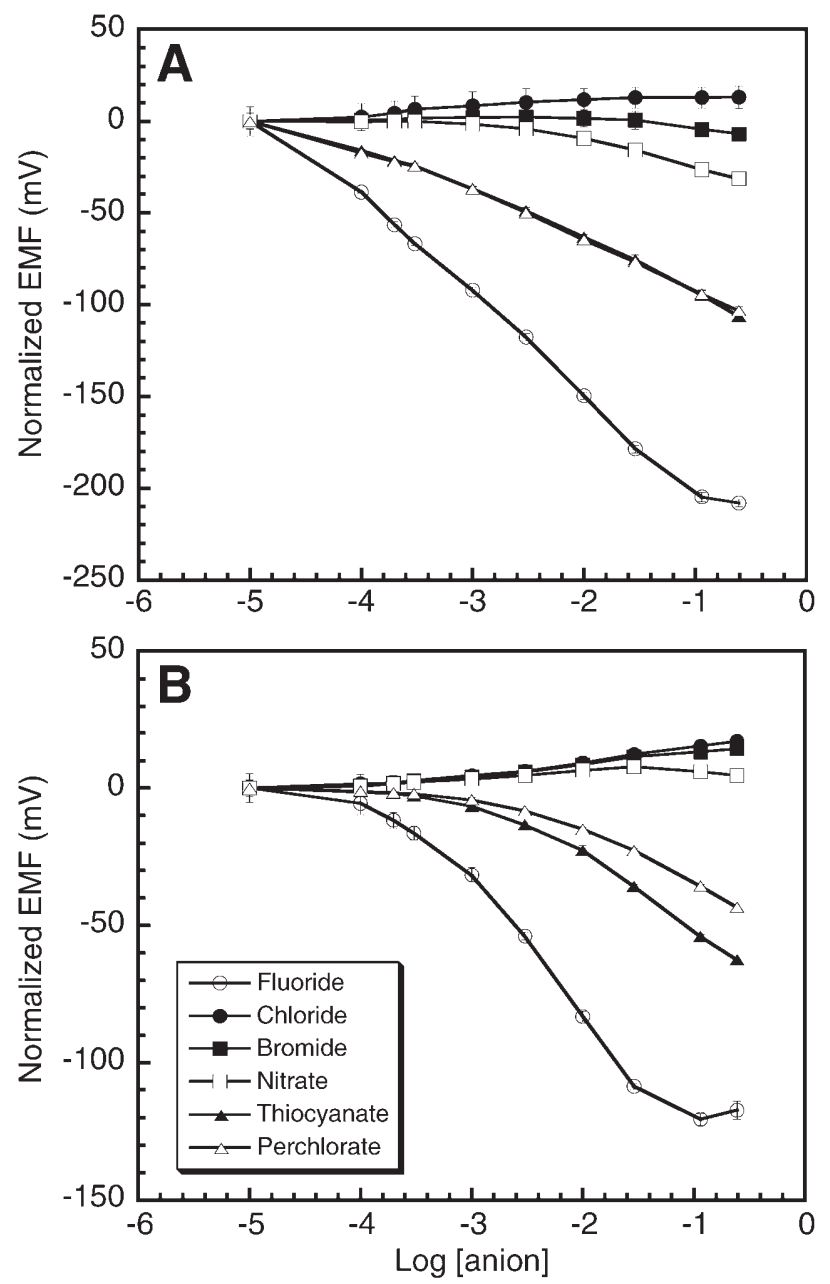

Fig. 2. Potentiometric anion response of PVC/DOS electrodes containing $\mathrm{Al}(\mathrm{III})$ porphyrins and $50 \mathrm{~mol} \%$ borate (relative to $\mathrm{Al}(\mathrm{III})$ ): A) Electrode VIII; B) Electrode XII. Internal solution: $0.01 \mathrm{NaCl} / \mathrm{NaF}$. Sample buffer: 0.05 M gly/phos, pH 3.0. 


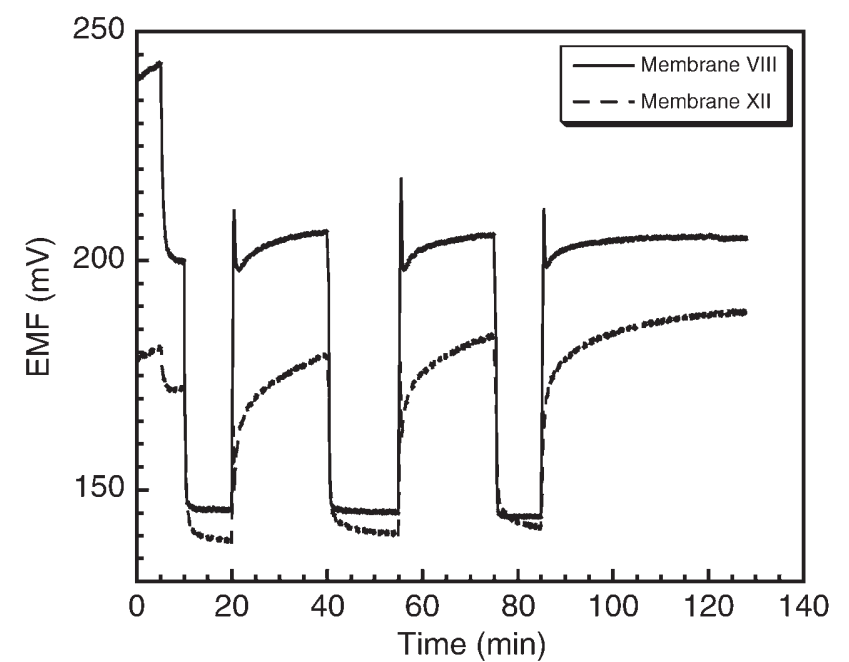

Fig. 3. Potentiometric dynamic response and reversibility to fluoride of $\mathrm{PVC} / \mathrm{DOS}$ electrodes containing $\mathrm{Al}(\mathrm{III})$ porphyrins. Fluoride concentration cycled between $4 \times 10^{-4} \mathrm{M}$ and $4 \times 10^{-3} \mathrm{M}$ in $0.05 \mathrm{M}$ gly/phos, $\mathrm{pH}$ 3.0.

pH 3.0 and absorbance bands were observed at $421 \mathrm{~nm}$ (Soret band) and $406 \mathrm{~nm}$ (dashed line in Figure 4). Optical spectra were also recorded after the film was equilibrated in solutions containing increasing concentrations of fluoride. After the first fluoride equilibration $\left(10^{-4} \mathrm{M}\right)$, the Soret band increased in intensity while the absorbance at $406 \mathrm{~nm}$ actually decreased. However, as total fluoride concentration was then increased $\left(10^{-3}, 10^{-2}\right.$, and finally $\left.10^{-1} \mathrm{M}\right)$, the Soret band continually decreased in intensity with the concomitant appearance and increase of a new band at $403 \mathrm{~nm}$. Since previous studies have shown a hypsochromic shift in the $\lambda_{\max }$ for dimeric metalloporphyrins in polymeric films (compared to monomers), the spectral data shown in Figure 4 demonstrates the possibility that a bridging-fluoride dimer may form when the film is exposed to fluoride. When the membrane is soaked in a solution containing only chloride (the initial internal solution composition employed to obtain the data shown in Figure 1), no changes in the optical absorbance spectrum are observed indicating that the effect is a direct result of fluoride (data not shown). In addition, it is possible that membranes that had never been exposed to fluoride undergo a non-equilibrium extraction of fluoride even in the absence of fluoride bridge dimer formation. This could partly explain the super-Nernstian behavior observed as the fluoride concentration was increased in the test solution, and fluoride is absent in the internal solution (so-called Hulanicki effect [37]). Indeed, as fluoride ions are introduced to the test solution, they are quickly extracted into the polymer phase because of their strong binding affinity for Al(III). Dimers then spontaneously form creating non-equilibrium conditions that could be responsible for the observed non-Nernstian slopes. When fluoride is added to the internal solution and the films are equilibrated, some degree of fluoride bridged dimers form so that increasing the sample concentration of fluoride has less effect on the degree of dimers in the film. Thus, the presence of this internal solution partially buffers the

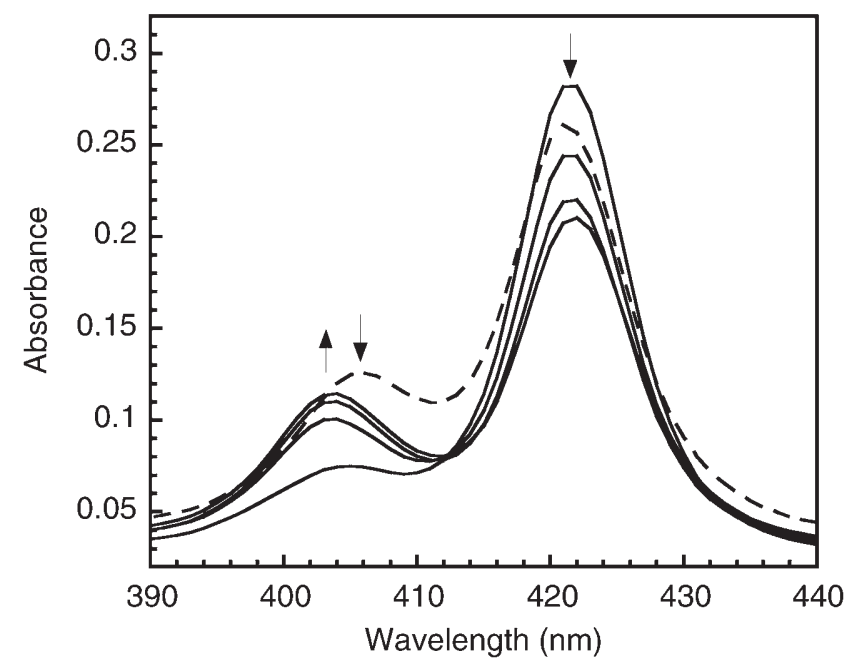

Fig. 4. Electronic absorption spectra of a membrane containing Al(III)-TPP and $50 \mathrm{~mol} \%$ borate (relative to $\mathrm{Al}(\mathrm{III})$ ) upon increasing the bathing concentration of fluoride. $(---)$ initial spectrum equilibrated in buffer.

membrane with respect to fluoride, allowing for nearNernstian behavior to be observed.

While near theoretical slopes can be achieved by adding fluoride ion to the internal solution, slow response times and sluggish reversibility persists for sensors formulated with $\mathrm{Al}(\mathrm{III})$-TPP or Al(III)-OEP. Variation of plasticizer (DOS, NPOE, or TOP), polymer membrane (PVC, PU, carboxylated-PVC), or membrane additives (in addition to KTFPB) proved to be ineffective in improving electrode performance (data not shown).

\subsection{Potentiometric Response Characteristics of Electrodes Formulated with AI(III)-PFP}

Although Al(III)-OEP and Al(III)-TPP based membranes exhibited good selectivity towards fluoride, the responses characteristics were less than desirable due to the nonequilibrium processes that appear to take place within the polymer film. Similar difficulties were observed previously with indium(III), gallium(III), and zirconium(IV) porphyrins as ionophores [9, 12, 34, 35]. Recently, two strategies have been employed to eliminate dimer-monomer chemistry within the sensing membranes and improve overall electrode performance: (1) covalent attachment of the ionophore (In(III) porphyrin) to the polymer matrix [38], and (2) use of a porphyrin ligand with sufficient steric bulk (In(III)- or Ga(III)-picket fence porphyrin) [33]. While we have investigated both approaches for aluminum(III) porphyrins, covalent attachment proved to be difficult due to the very high Lewis acidity of $\mathrm{Al}(\mathrm{III})$. Therefore, commercially available PFP was metallated with Al(III) and employed as an ionophore (Al(III)-PFP) to prevent any dimer formation with the polymeric membrane of the fluoride sensing electrode.

Table 1 lists the membrane compositions examined that contain the Al(III)-PFP ionophore (electrodes XIV - XIX). 
All of these electrodes displayed near Nernstian response over a given fluoride ion concentration range (see Table 1) with only chloride present within the internal solution. The most promising EMF response was obtained with a $\mathrm{PVC} / o$ NPOE membrane containing $1 \mathrm{wt} \% \mathrm{Al}(\mathrm{III})$-PFP and $25 \mathrm{~mol} \%$ of KTFPB, yielding response from $6 \times 10^{-5} \mathrm{M}-$ $6 \times 10^{-2} \mathrm{M}$ fluoride concentration range with a slope of $-59.4 \mathrm{mV} / \mathrm{dec}$ (see Figure 5). Potentiometric response for this membrane composition did not exhibit any significant drift, and the data shown in Figure 5 did not require normalization. Further, when films of the same composition were examined using UV-Vis absorption spectroscopy, no evidence of any dimer formation was found in the absence or presence of fluoride, indicating that the steric hindrance within the PFP ligand eliminates the possibility of forming anion bridged dimers. The only changes in the spectrum $(2 \mathrm{~nm}$ blue shift of the Soret band) reflected the axial ligation of fluoride to $\mathrm{Al}(\mathrm{III})$ ion center of the porphyrin.

A comparison of the results obtained for Al(III)-PFP vs. $\mathrm{Al}(\mathrm{III})-\mathrm{TPP}$ or $\mathrm{Al}(\mathrm{III})$-OEP as ionophores (see Fig. 2) indicates that the $\mathrm{Al}(\mathrm{III})$-PFP system also provides far better selectivity. Table 2 lists the experimentally determined potentiometric selectivity coefficients for the three ionophore systems (based on separate solution method [39]). Electrode XV with $\mathrm{Al}(\mathrm{III})$-PFP exhibits the best reported potentiometric fluoride selectivity of any ionophore system reported to date in the literature, with potentiometric selectivity coefficients for fluoride over lipophilic anions such perchlorate $\left(\log k_{\mathrm{F}-/ \mathrm{ClO} 4-}=-4.2\right)$

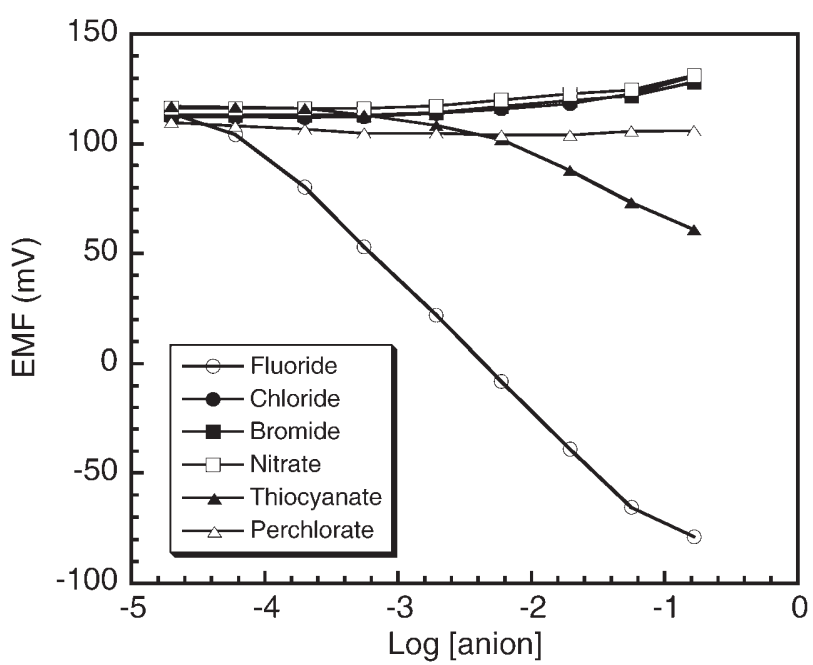

Fig. 5. Potentiometric anion responses of PVC/NPOE electrodes containing $1 \mathrm{wt} \% \mathrm{Al}(\mathrm{III})$-PFP and $25 \mathrm{~mol} \%$ borate (relative to $\mathrm{Al}(\mathrm{III})$ ) (Electrode XV). Sample buffer: 0.05 M gly/phos, pH 3.0. and thiocyanate $\left(\log k_{\mathrm{F}-/ \mathrm{SCN}-}=-3.0\right)$ far lower than other ionophore systems (see Table 2). It should be noted that because the slopes of all anions' calibration curves (other than fluoride) were non-Nernstian, it is not possible to determine selectivity coefficients with a high degree of accuracy. The values presented in Table 2 allow for comparison between different membrane compositions and previous reports, but a more appropriate measure of selectivity when electrodes exhibit non-Nernstian behavior to interferent ions is to display of the relative EMF response curves, as illustrated in Figure 5 [39]. It can be seen that there is negligible response toward all other anions tested when using $\mathrm{Al}(\mathrm{III})$-PFP as the membrane ionophore. The only significant interference for fluoride sensors based on $\mathrm{Al}$ (III) porphyrins is hydroxide ion. Indeed, an estimation of the potentiometric selectivity coefficient for fluoride vs. hydroxide can best be obtained using the fixed interferent method [39]. Values of $\log k_{\mathrm{F}-\mathrm{OOH}-}$ estimated using this method are in the range of $+6.0-6.5$ for the various $\mathrm{Al}(\mathrm{III})$ porphyrin ionophores. As observed for most of the metalloporphyrin ionophore systems reported to date, hydroxide is very strong axial ligand for the $\mathrm{Al}(\mathrm{III})$ center, and this necessitates use of $\mathrm{pH} 3.0$ buffered samples to achieve optimal detection limits for fluoride.

Another crucial response parameter that characterizes the ability of $\mathrm{Al}(\mathrm{III})$-PFP to remain as a monomer within the membranes of the electrodes is the response and recover times. As shown in Figure 6, electrode XV shows quite rapid and fully reversible EMF response toward fluoride. Stable EMF response was achieved in ca. $1 \mathrm{~min}$ after additions of fluoride to the test solution ( $\mathrm{pH}$ 3.0) and full reversibility is achieved in ca. $2-3 \mathrm{~min}$. This is much faster than that obtained with the $\mathrm{Al}(\mathrm{III})-\mathrm{TPP}$ or $\mathrm{Al}(\mathrm{III})$-OEP ionophores, even with fluoride added to the internal solutions of the electrodes.

One potential drawback of the present $\mathrm{Al}(\mathrm{III})$-PFP ionophore system is the relatively short electrode lifetime. Indeed, the slope of the fluoride calibration curve decreases from -59 to $-50 \mathrm{mV} / \mathrm{dec}$ after one week. This is attributed to leaching of $\mathrm{Al}(\mathrm{III})$-PFP into the aqueous conditioning solutions and also its crystallization within the membrane phase. Synthesis of a more lipophilic picket fence type $\mathrm{Al}(\mathrm{III})$ porphyrin structure should overcome this current limitation.

\section{Conclusions}

Based on the data presented above, $\mathrm{Al}(\mathrm{III})$ porphyrins appear to offer great promise as potential ionophores in

Table 2. Potentiometric selectivity coefficients for various membrane compositions tested using $\mathrm{Al}(\mathrm{III})$-TPP, $\mathrm{Al}(\mathrm{III})$-OEP, and $\mathrm{Al}(\mathrm{III})-$ PFP as ionophores.

\begin{tabular}{llllll}
\hline Membrane/electrode & $\log k_{\mathrm{F}, \mathrm{Cl}}{ }^{\mathrm{pot}}$ & $\log k_{\mathrm{F}, \mathrm{Br}}{ }^{\mathrm{pot}}$ & $\log k_{\mathrm{F}, \mathrm{NO} 3^{\mathrm{pot}}}$ & $\log k_{\mathrm{F}, \mathrm{CCN}}{ }^{\mathrm{pot}}$ & $\log k_{\mathrm{F}, \mathrm{ClO} 4^{\mathrm{pot}}}$ \\
\hline VIII & -1.8 & -2.1 & -2.1 & -1.3 & -1.5 \\
XII & -1.1 & -1.3 & -1.4 & -1.0 & -1.3 \\
XV & -4.4 & -4.3 & -4.3 & -3.0 & -4.2 \\
\hline
\end{tabular}




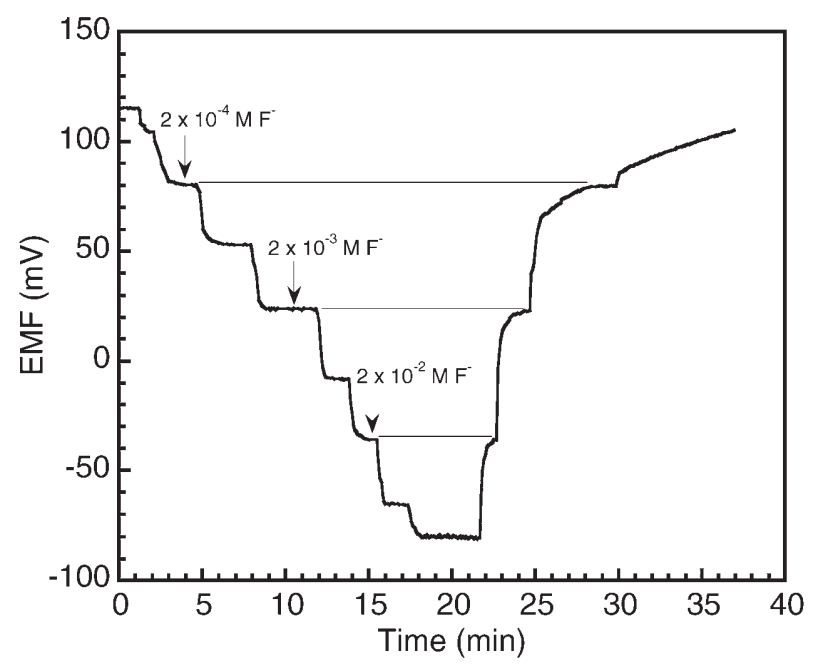

Fig. 6. Potentiometric dynamic response and reversibility to fluoride of electrode XV. Sample buffer: $0.05 \mathrm{M}$ gly/phos, $\mathrm{pH}$ 3.0. Horizontal lines represent equal concentrations.

developing fluoride selective polymeric membrane electrodes. When $\mathrm{Al}(\mathrm{III})-\mathrm{TPP}$ and $\mathrm{Al}(\mathrm{III})-\mathrm{OEP}$ are used as ionophores, the resulting electrodes display selective response toward fluoride, but with slow response and recovery times. Optical absorbance data suggest that these porphyrins likely form fluoride bridged dimers within the organic membrane phase upon increasing analyte fluoride levels in the sample. Such dimerization can be prevented by using a sterically hindered porphyrin ionophore, Al(III)-PFP, which enables fabrication of electrodes with vastly improved fluoride response and selectivity, and no evidence of dimer-monomer chemistry in the membrane phase. However, detection limits in this system $(20 \mu \mathrm{M})$ are still somewhat higher than desired (e.g., $1 \mu \mathrm{M}$ ) and further studies are needed to determine membrane formulations or test conditions that will enable lower levels of fluoride to be detected reliably.

\section{Acknowledgements}

We thank the National Institutes of Health (grant EB 000784) for support of this research. EM and MP gratefully acknowledge the Warsaw University of Technology for partial financial support of this work. The authors also thank Ibrahim Badr for helpful discussions.

\section{References}

[1] E. Bakker, P. Buhlmann, E. Pretsch, Chem. Rev. 1997, 97, 3083.

[2] P. Buhlmann, E. Pretsch, E. Bakker, Chem. Rev. 1998, 98, 1593.

[3] M. M. G. Antonisse, D. N. Reinhoudt, Electroanalysis 1999, $11,1035$.

[4] F. Hofmeister, Arch. Exp. Pathol. Pharmakol. 1888, 24, 247.
[5] N. A. Chaniotakis, A. M. Chasser, M. E. Meyerhoff, J. T. Groves, Anal. Chem. 1988, 60, 185.

[6] L. Gorski, E. Malinowska, Anal. Chim. Acta 2005, 540, 159.

[7] L. Gorski, M. E. Meyerhoff, E. Malinowska, Talanta 2004, 63, 101.

[8] C. E. Kibbey, S. B. Park, G. DeAdwyler, M. E. Meyerhoff, J. Electroanal. Chem. 1992, 60, 135.

[9] E. Malinowska, L. Gorski, M. E. Meyerhoff, Anal. Chim. Acta 2002, 468, 133.

[10] E. Malinowska, M. E. Meyerhoff, Anal. Chim. Acta 1995, $300,33$.

[11] E. Malinowska, J. Niedziolka, M. E. Meyerhoff, Anal. Chim. Acta 2001, 432, 67.

[12] E. D. Steinle, U. Schaller, M. E. Meyerhoff, Anal. Sci. 1998, $14,79$.

[13] H. Hattori, M. Hoshino, T. Wakii, A. Yuchi, Anal. Chem. 2004, 76, 5056.

[14] S. Shahrokhian, A. Hamzehloei, M. Bagherzadeh, Anal. Chem. 2002, 74, 3312.

[15] M. Shamsipur, M. Javanbakht, A. R. Hassaninejad, H. Sharghi, M. R. Ganjali, M. F. Mousavi, Electroanalysis 2003, 15, 1251.

[16] X. Chen, C.-G. Zhan, J. Phys. Chem. A 2004, 108, 6407.

[17] P. E. Rakita, J. Chem. Ed. 2004, 81, 677.

[18] A. L. Simonian, J. K. Grimsley, A. W. FLounders, J. S. Schoeniger, T.-C. Cheng, J. J. DeFrank, J. R. Wild, Anal. Chim. Acta 2001, 442, 15.

[19] M. Panunzio, K. Rossi, E. Tamanini, E. Campana, G. Martelli, Tetrahedron Asymmetry 2004, 15, 3489.

[20] M. S. Frant, J. W. Ross, Science 1966, 154, 1553.

[21] M. M. G. Antonisse, B. H. M. Snellink-Ruel, A. C. Ion, E. J. F. J., D. N. Reinhoudt, J. Chem. Soc. Perkin Trans. 2 1999, 1211.

[22] P. Perdikaki, I. Tsagkatakis, N. A. Chaniotakis, R. Altmann, K. Jurkschat, G. Reeske, Anal. Chim. Acta 2002, 467, 197.

[23] J. T. Mitchell-Koch, E. Malinowska, M. E. Meyerhoff, Electroanalysis 2005, 17, 1347.

[24] I. H. A. Badr, M. E. Meyerhoff, J. Am. Chem. Soc. 2005, 127, 5318.

[25] I. H. A. Badr, M. E. Meyerhoff, Anal. Chem. 2005, 77, 6719.

[26] A. D. Adler, F. R. Longo, J. D. Finarelli, J. Goldmacher, J. Assour, L. Korsakoff, J. Org. Chem. 1967, 32, 476.

[27] Y. Kaizu, N. Misu, K. Tsuji, Y. Kaneko, H. Kobayashi, Bull. Chem. Soc. Jpn. 1985, 58, 103.

[28] T. Aida, S. Inoue, J. Am. Chem. Soc. 1983, 105, 1304.

[29] T. Aida, K. Wada, S. Inoue, Macromolecules 1987, 20, 237.

[30] D. D. Perrin, W. L. F. Armarego, Purification of Laboratory Chemicals, 3rd ed., Pergamon Press, New York 1988.

[31] E. Bakker, E. Malinowska, R. D. Schiller, M. E. Meyerhoff, Talanta 1994, 41, 881.

[32] P. G. Parzuchowski, J. W. Kampf, E. Roznieka, Y. Kondratenko, E. Malinowska, M. E. Meyerhoff, Inorg. Chim. Acta 2003, 355, 302.

[33] E. D. Steinle, S. Amemiya, P. Buhlmann, M. E. Meyerhoff, Anal. Chem. 2000, 72, 5766.

[34] W. Zhang, E. Rozniecka, E. Malinowska, P. G. Parzuchowski, M. E. Meyerhoff, Anal. Chem. 2002, 74, 4548.

[35] W. Qin, P. G. Parzuchowski, W. Zhang, M. E. Meyerhoff, Anal. Chem. 2003, 75, 332.

[36] C. Becker, I. Kieltsch, D. Broggini, A. Mezzetti, Inorg. Chem. 2003, $42,8417$.

[37] A. Hulanicki, R. Lewandowski, Chem. Anal. Warsaw 1974, $19,53$.

[38] Y. Qin, E. Bakker, Anal. Chem. 2004, 76, 4379.

[39] E. Bakker, E. Pretsch, P. Buhlmann, Anal. Chem. 2000, 72, 1127. 